\title{
A numerical study of the convective heat transfer between a room and a window covered by a partially open plane blind with a gap at the top
}

\author{
P. H. Oosthuizen \\ Department of Mechanical and Materials Engineering, \\ Queen's University, Canada
}

\begin{abstract}
An approximate model of a window covered by a partially open plane blind has been considered. The window is represented by a vertical isothermal wall section which is exposed to a large surrounding room in which the mean temperature is lower than the window temperature. The blind is represented by a thin straight vertical wall which offers no resistance to heat transfer across it. The top of this thin section is aligned with the top of the heated wall section. There is a thin horizontal wall section at the top of the "blind". This horizontal section does not fully reach to the vertical wall with the result that there is a small gap between the blind system and the vertical wall. The main purpose of this study was to determine the effect of the size of this gap on the heat transfer rate from the "window" to the room. The length of the thin vertical wall section is, in general, less than the height of the window and thus represents a partially open blind. Attention has only been given to the convective heat transfer from the window. The governing equations, written in dimensionless form, have been solved using a commercial finite-element based code. The solution has the following parameters: Rayleigh number, Prandtl number, dimensionless horizontal distance between the window and the blind, dimensionless distance of the bottom of the blind above the bottom of the window and dimensionless size of the gap at the top of the window. Results have only been obtained for a Prandtl number of 0.7. Keywords: heat transfer, convection, windows, shading, blinds, numerical.
\end{abstract}




\section{Introduction}

Blinds and other forms of covering can be used to reduce building energy use and improved models for the effects of blinds on window heat transfer are needed to assist in the development of systems that make the maximum use of blinds for this purpose. The situation considered in the present study is an approximate model of a window covered by a partially open plane blind. The present work was undertaken as part of a wider study of the effect of window coverings on the heat transfer rate from windows, particularly for the case where the window is hotter than the room air, i.e., for the case where air-conditioning is being used. The situation considered is shown in fig. 1. In this situation, the window is represented by a vertical isothermal wall section with parallel adiabatic wall sections above and below the heated section. This heated wall section (the "window") is exposed to a large surrounding room in which the mean temperature is assumed to be known and lower than the window temperature. The plane blind is represented by a thin straight vertical wall which offers no resistance to heat transfer across it and in which conductive heat transfer is negligible. The top of this thin wall section (i.e., of the "blind") is aligned with the top of the heated wall section (i.e., with the top of the "window. There is a thin horizontal wall section at the top of the "blind" which is thus normal to the "blind". This horizontal section does not fully reach to the vertical wall with the result that there is a small gap between the blind system and the vertical wall.
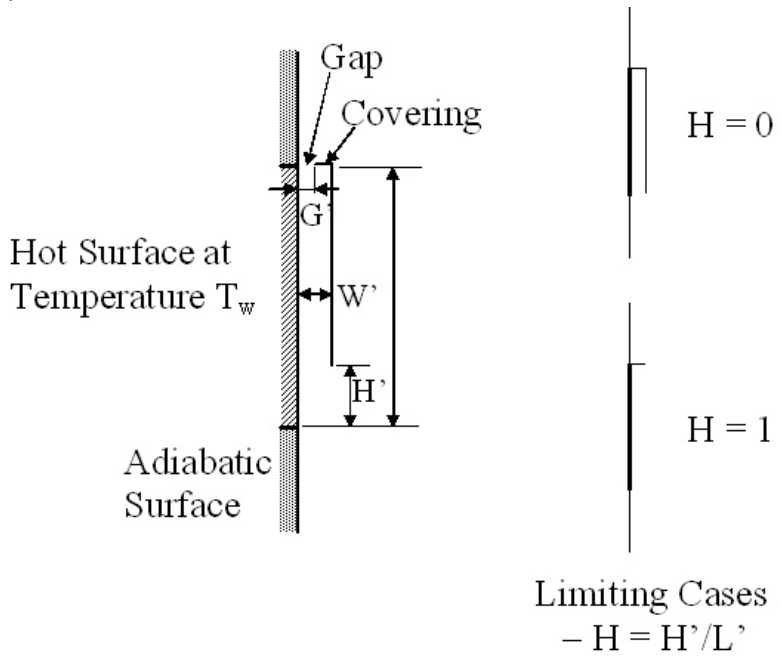

Figure 1: $\quad$ Situation considered. The two limiting cases of a fully open $(\mathrm{H}=1)$ and a fully closed $(\mathrm{H}=0)$ "blind" are shown on the right.

The main purpose of this study was to determine the effect of the dimensionless size of this gap on the heat transfer rate from the "window" to the room. The length of the thin vertical wall section (i.e., of the "blind") is, in 
general, less than the height of the window and thus represents a partially open plane or roller blind. Attention has only been given to the convective heat transfer from the window, i.e., radiative heat transfer and the effects of solar radiation have not been considered. Although the model used here is only an approximation of the real situation, the results obtained with this model will give an indication of the effect of the governing parameters on the convective heat transfer rate from an actual window.

The present work was undertaken as part of a wider study of the effect of window coverings on the heat transfer rate from windows particularly for the case where the window is hotter than the room air, i.e. where air-conditioning is being used, see for example Collins et al. [1-3], Machin et al. [4], Shahid et al. [5]. These studies and those described by Duarte et al. [6] and Phillips et al. [7] have concentrated on Venetian blinds. Some studies involving vertical blinds have also been undertaken, e.g., see Oosthuizen et al. [8-10]. Some studies of situations involving plane blinds have been undertaken, e.g., see Oosthuizen [11-13]. However these studies have not considered the effect of a gap between the wall and the top of the window-blind system. The present study, as is the case in many of the previous studies mentioned above, considers only the convective heat transfer. In window heat transfer situations the radiant heat transfer can however be very important and can interact with the convective flow, e.g. see Collins et al. [1] and Phillips et al. [14].

\section{Solution procedure}

The flow has been assumed to be laminar and two-dimensional. Fluid properties have been assumed constant except for the density change with temperature that gives rise to the buoyancy forces, this being treated by means of the Boussinesq type approximation. The covering over the heated wall section (the "blind") has been assumed to offer no resistance to heat transfer and to have negligible thickness so that conduction along it is negligible. The effects of radiative heat transfer have been neglected. The governing equations have been written in terms of dimensionless variables using the height, L', of the heated wall section (the "window") as the length scale and the overall temperature difference $\left(\mathrm{T}_{\mathrm{w}}\right.$ $T_{a}$ ) as the temperature scale, $T_{a}$ being the air temperature in the "room" to which the window is exposed. It has been assumed that the "window" temperature, $T_{w}$, is higher than the temperature of the air in the "room". The resultant dimensionless equations have been solved using a commercial finite-element based code, FIDAP. Only the mean heat transfer rate from the isothermal surface (the "blind") will be considered here. This has been expressed in terms of a mean Nusselt number, $\mathrm{Nu}$, based on the window height, L', and on the overall temperature difference $\left(T_{w}-T_{a}\right)$. 


\section{Results}

The dimensionless governing equations have the following parameters:

1. the Rayleigh number based on the window height, $L$, and on $\left(T_{w}-T_{a}\right)$, $\mathrm{Ra}$

2. the Prandtl number, $\operatorname{Pr}$

3. the dimensionless horizontal distance between the window and the blind, $\mathrm{W}=\mathrm{W}$ ' / L'

4. the dimensionless distance of the bottom of the blind above the bottom of the window, $\mathrm{H}=\mathrm{H}^{\prime} / \mathrm{L}$ '.

5. the dimensionless gap between the horizontal top section of the blind system and the top of the window, $\mathrm{G}=\mathrm{G}^{\prime}$ / L'.

Here, as shown in fig. 1, G' is the size of gap between the top of "blind system" and "wall", $H$ ' is the height of bottom of thin wall section (i.e., of the "blind") above bottom of heated wall section (i.e., of the "window") and W' is the distance of thin vertical wall section (i.e., the "blind") from the heated wall section (i.e., the "window").

Because of the application being considered, results have only been obtained for a Prandtl number of 0.7. Rayleigh numbers of between $10^{3}$ and $10^{8}$, $\mathrm{H}$ values of between 0 and $1, \mathrm{~W}$ values of between 0.02 and 0.12 , and $\mathrm{G}$ values of between 0 and $\mathrm{W}$ have been considered. An $\mathrm{H}$ value of 0 corresponds to a "fullyclosed blind" while an $\mathrm{H}$ value of 1 corresponds to a "fully-open blind", these two cases being shown in fig. 1. Results were also obtained for the no-blind case and the mean Nusselt numbers given for this case were found to be in excellent agreement with values given by empirical equations for the mean natural convective heat transfer rate from an isothermal vertical flat plate.

The effect of the dimensionless gap $G$ on the mean Nusselt number for various values of $\mathrm{H}$ and for Rayleigh numbers of $10^{5}, 10^{6}$ and $10^{7}$ is shown in figs. 1, 2 and 3 respectively. These results are all for $\mathrm{W}=0.1$. It will be seen from these figures that the gap size has the biggest effect on the heat transfer rate when the Rayleigh number is low and the gap size is small. For example, it will be seen from fig. 2 that for a Rayleigh number of $10^{5}$ the value of $\mathrm{G}$ has quite a significant effect on the Nusselt number at all values of $\mathrm{G}$ whereas it will be seen from fig. 4 that for a Rayleigh number of $10^{7}$ the value of $\mathrm{G}$ only has a significant effect on the Nusselt number when $G$ is less than greater than about 0.03. This is because at low Rayleigh numbers the thickness of the boundary layer on the "window" is relatively large and significantly greater than the gap size whereas at high Rayleigh numbers the thickness of the boundary layer on the "window" is relatively small and can be significantly less than G with the result that the gap size has only a small effect on the flow and therefore on the heat transfer rate. This is illustrated by the typical streamline patterns shown in fig. 5 . 


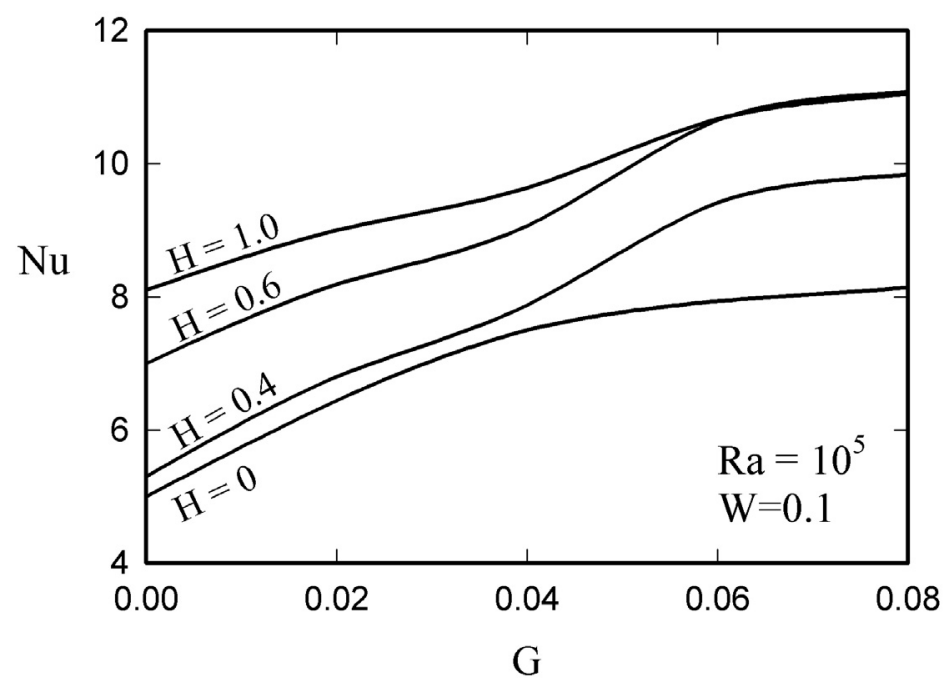

Figure 2: $\quad$ Variation of mean Nusselt number with dimensionless gap size $\mathrm{G}$ for various values of $\mathrm{H}$ for $\mathrm{W}=0.1$ and $\mathrm{Ra}=10^{5}$.

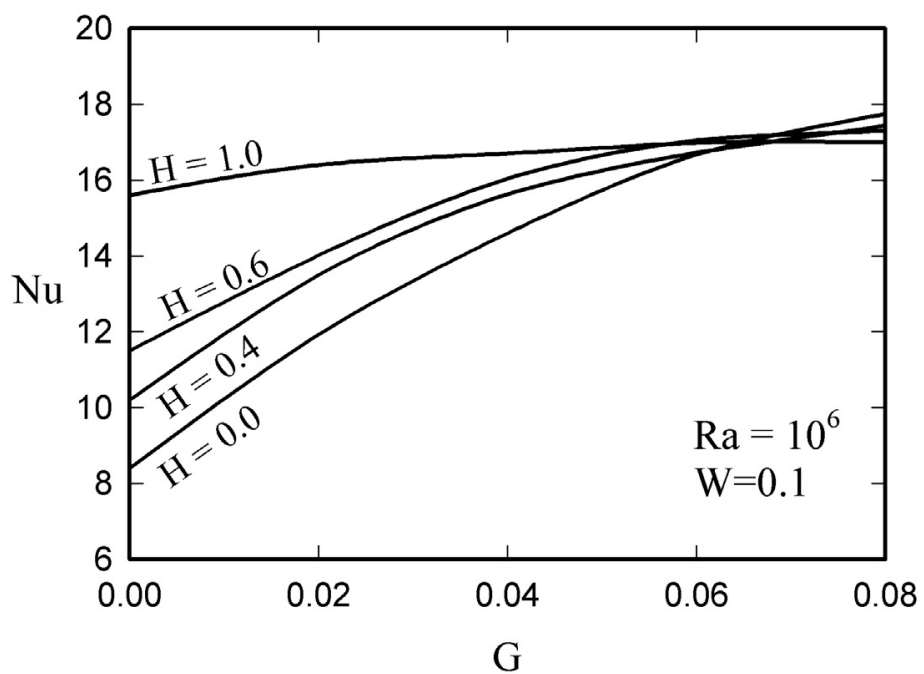

Figure 3: Variation of mean Nusselt number with dimensionless gap size $\mathrm{G}$ for various values of $\mathrm{H}$ for $\mathrm{W}=0.1$ and $\mathrm{Ra}=10^{6}$. 
18 Advanced Computational Methods in Heat Transfer IX

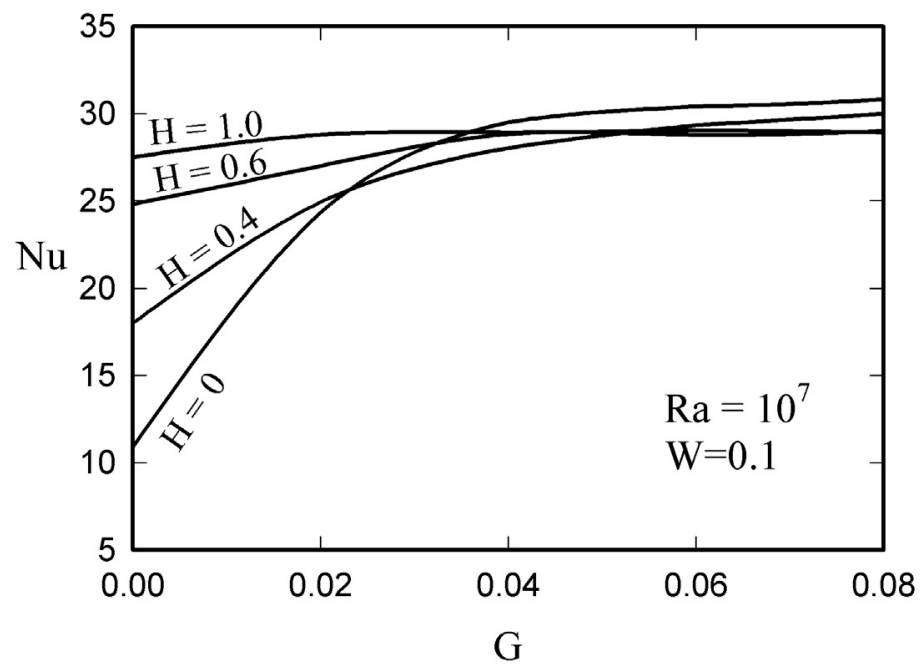

Figure 4: Variation of mean Nusselt number with dimensionless gap size $\mathrm{G}$ for various values of $\mathrm{H}$ for $\mathrm{W}=0.1$ and $\mathrm{Ra}=10^{7}$.

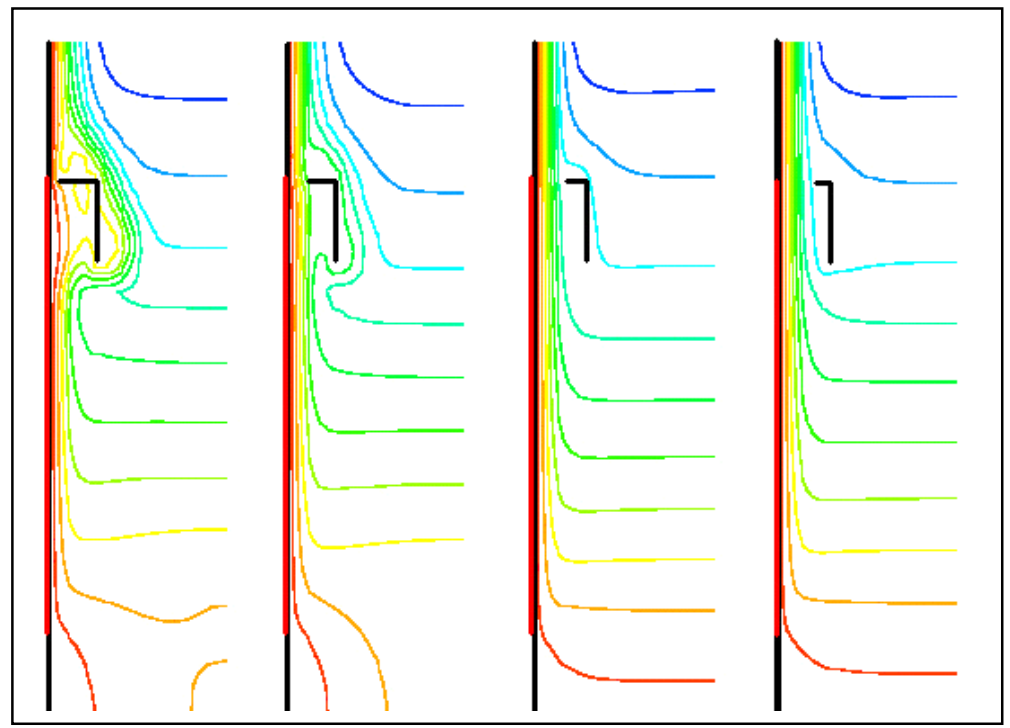

Figure 5: Streamline patterns for $\mathrm{W}=0.1, \mathrm{H}=0.8$ and $\mathrm{Ra}=10^{7}$ for $\mathrm{G}$ values of from left to right of $0.02,0.04,0.06$, and 0.08 . 
The effect of the dimensionless "blind - window" spacing W on the mean Nusselt number is illustrated by the results given in figs. 6 and 7. It will be seen from these results that as $\mathrm{W}$ increases the mean Nusselt decreases but it then passes through a minimum and then increases with increasing $\mathrm{W}$. This form of behaviour arises because when $\mathrm{W}$ is small then is very little convective motion in the air between the blind and the window and the heat transfer is mainly by conduction and heat transfer rate decreases as the thickness of the air layer increases. However as $\mathrm{W}$ increases further, convective motion begins between the blind and the window and this tends to increase the heat transfer rate and thus leading the minimum in the $\mathrm{Nu}-\mathrm{W}$ variation. It will also be seen from the results given in figs. 6 and 7 that the value of $\mathrm{W}$ at which the minimum heat transfer rate occurs increases with $\mathrm{H}$ at the smaller value of $\mathrm{H}$ considered. The form of the variation of the Nusselt number with dimensionless blind opening, $\mathrm{H}$, is illustrated by the results given in fig. 8 . It will be seen that as the result of the presence of the top gap, the mean Nusselt number does vary linearly with $\mathrm{H}$ as is sometimes assumed.

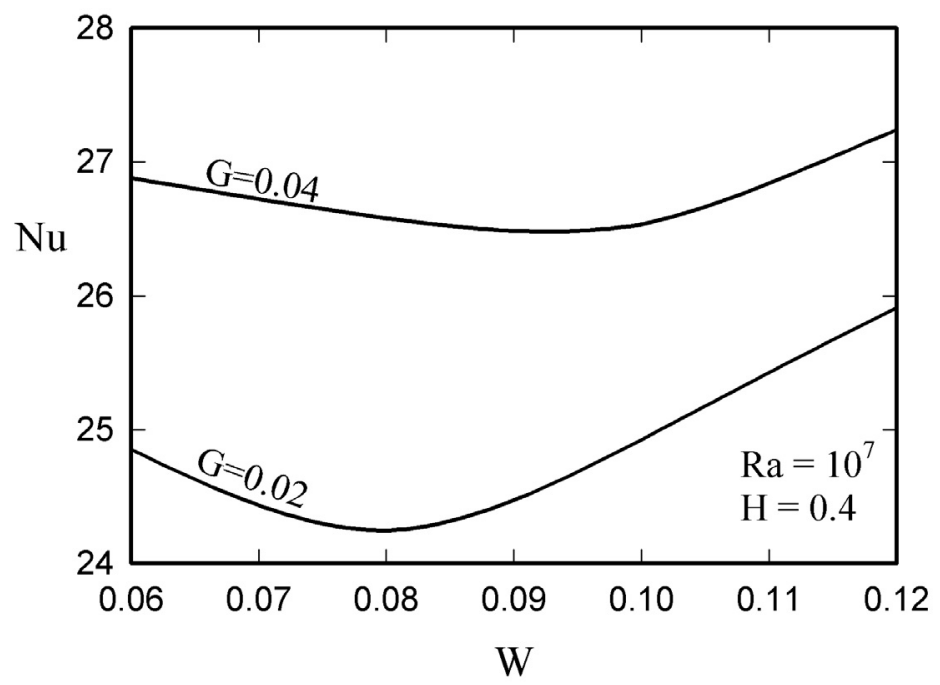

Figure 6: Variation of mean Nusselt number with dimensionless window-blind spacing, W, for a Rayleigh number of $10^{7}$ and $\mathrm{H}=0.4$ for two values of $\mathrm{G}$. 


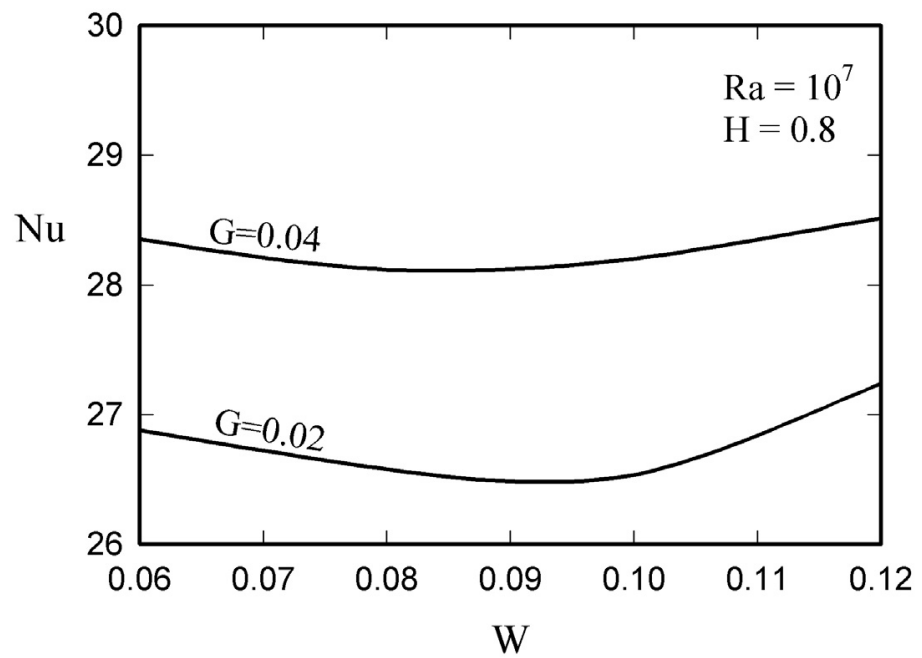

Figure 7: Variation of mean Nusselt number with dimensionless window-blind spacing, $\mathrm{W}$, for a Rayleigh number of $10^{7}$ and $\mathrm{H}=0.8$ for two values of $\mathrm{G}$.

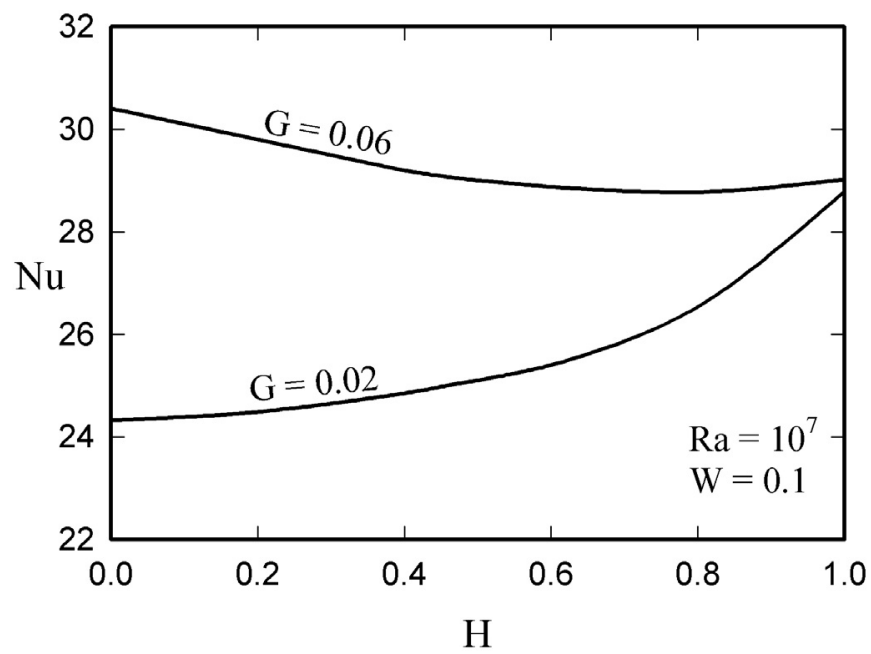

Figure 8: Variation of mean Nusselt number with dimensionless blind opening $\mathrm{H}$ for a Rayleigh number of $10^{7}$ and $\mathrm{W}=0.1$ for two values of $\mathrm{G}$. 


\section{Conclusions}

The dimensionless blind opening, $\mathrm{H}$, has been shown to have a very significant affect on the mean Nusselt number, the results given here allowing an estimate to be made of this effect for various values of $\mathrm{Ra}$ and $\mathrm{W}$.

\section{Acknowledgment}

This work was supported by the Natural Sciences and Engineering Research Council of Canada.

\section{References}

[1] Collins, M., Harrison, S.J., Oosthuizen, P.H. \& Naylor, D., Sensitivity analysis of heat transfer from an irradiated window and horizontal louvered blind assembly. American Society of Heating, Refrigerating and Air-Conditioning Engineers (ASHRAE) Trans., 108, pp. 1-8, 2002.

[2] Collins, M.R., Harrison, S.J., Naylor, D., \& Oosthuizen, P.H., Heat transfer from an isothermal vertical plate with adjacent heated horizontal louvers: Numerical analysis. J. Heat Transfer, 124(6), pp. 1072-1077, 2002.

[3] Collins, M.R., Harrison, S.J., Naylor, D., \& Oosthuizen, P.H., Heat transfer from an isothermal vertical plate with adjacent heated horizontal louvers: Validation. J. Heat Transfer, 124(6), pp. 1078-1087, 2002.

[4] Machin, A.D., Naylor, D., Oosthuizen, P.H., \& Harrison, S.J., Experimental study of free convection at an indoor glazing surface with a Venetian blind. J. HVAC\&R Research, 4(2), pp. 153-166, 1998.

[5] Shahid, H., Naylor, D., Oosthuizen, P.H., \& Harrison, S.J., A numerical study of the effect of horizontal louvered blinds on window thermal performance. Paper SH2. Proc. of the $2^{\text {nd }}$ Int. Conf. on Heat Transfer, Fluid Mechanics and Thermodynamics (HEFAT), ed. J.P. Meyer, pp. 1-6, 2003

[6] Duarte, N., Naylor, D., Oosthuizen, P.H. \& Harrison, S.J., An interferometric study of free convection at a window glazing with a heated Venetian blind. Int. J. HVAC\&R Research, 7(2), pp. 169-184, 2001.

[7] Phillips, J., Naylor, D., Harrison, S.J., \& Oosthuizen, P.H., Free convection from a window glazing with a Venetian blind: Numerical model development. Trans. CSME, 23(1B), pp. 159-172, 1999.

[8] Oosthuizen, P.H., Sun, L., \& Naylor, D., A numerical study of the effect of normal adiabatic surfaces on natural convective heat transfer from a vertical isothermal plate. Progress in Transport Phenomena, Proc. of the $3^{\text {rd }}$ Int. Symposium on Transport Phenomena, eds. S. Dost, H. Struchtrup, \& I Dincer, Elsevier: Paris, pp. 327-331, 2002.

[9] Oosthuizen, P.H., Sun, L., \& Naylor, D., The effect of inclined vertical slats on natural convective heat transfer from an isothermal heated vertical 
plate. Proc. Of the $10^{\text {th }}$ Annual Conf. of the CFD Society of Canada, pp. 515-519, 2002.

[10] Oosthuizen, P.H., Sun, L., \& Naylor, D., The effect of heat generation in inclined slats in natural convection from an isothermal heated vertical plate. Proc. Of the $11^{\text {th }}$ Annual Conf. of the CFD Society of Canada, pp. 1-8, 2003.

[11] Oosthuizen, P.H., Natural convection in a square enclosure with a partially heated wall section covered by a blind-like attachment with heat generation in the attachment. Proc. Of the $1^{\text {st }}$ Int. Conf, on Heat Transfer, Fluid Mechanics and Thermodynamics (HEFAT), Skukuza, Kruger National Park, South Africa, Vol. 1, Part 2, pp. 702-707, 2002.

[12] Oosthuizen, P.H., Natural convection in a square enclosure with a partially heated wall section covered by a blind-like attachment with nonuniform heat generation in the attachment. Progress in Transport Phenomena, Proc. of the $3^{\text {rd }}$ Int. Symposium on Transport Phenomena, eds. S. Dost, H. Struchtrup \& I. Dincer, Elsevier: Paris, pp. 29-34, 2002.

[13] Oosthuizen, P.H., Natural convection in a square enclosure with a partially heated wall section covered by a blind-like attachment in which there is a linearly varying heat transfer rate, Paper IMECE2002-32968, Proc. On CD of IMECE2002, Vol. 1, 2002.

[14] Phillips, J., Naylor, D., Harrison, S.J., \& Oosthuizen, P.H., Numerical study of convective and radiative heat transfer from a window glazing with a Venetian blind. Int. J. of HVAC\&R Research, 7(4), pp. 383-402, 2001. 